\title{
Theory-Based Interventions to Improve Medication Adherence in Older Adults Prescribed Polypharmacy: A Systematic Review
}

\author{
Deborah E. Patton ${ }^{1}$ - Carmel M. Hughes ${ }^{1}$ Cathal A. Cadogan ${ }^{1,2}$. \\ Cristín A. Ryan ${ }^{1,2}$
}

Published online: 26 December 2016

(C) The Author(s) 2016. This article is published with open access at Springerlink.com

\begin{abstract}
Background Previous interventions have shown limited success in improving medication adherence in older adults, and this may be due to the lack of a theoretical underpinning. Objective This review sought to determine the effectiveness of theory-based interventions aimed at improving medication adherence in older adults prescribed polypharmacy and to explore the extent to which psychological theory informed their development.

Data Sources Eight electronic databases were searched from inception to March 2015, and extensive handsearching was conducted.

Eligibility Criteria Interventions delivered to older adults (populations with a mean/median age of $\geq 65$ years) prescribed polypharmacy (four or more regular oral/non-oral medicines) were eligible. Studies had to report an underpinning theory and measure at least one adherence and one clinical/humanistic outcome.

Review Methods Data were extracted independently by two reviewers and included details of intervention content, delivery, providers, participants, outcomes and theories used. The theory coding scheme (TCS) was used to assess the extent of theory use.
\end{abstract}

Electronic supplementary material The online version of this article (doi:10.1007/s40266-016-0426-6) contains supplementary material, which is available to authorized users.

Cristín A. Ryan

cristinryan@rcsi.ie

1 School of Pharmacy, Queen's University Belfast, 97 Lisburn Road, Belfast, United Kingdom

2 Present Address: School of Pharmacy, Royal College of Surgeons in Ireland, 111 St. Stephens Green, Dublin 2, Ireland
Results Five studies cited theory as the basis for intervention development (social cognitive theory, health belief model, transtheoretical model, self-regulation model). The extent of theory use and intervention effectiveness in terms of adherence and clinical/humanistic outcomes varied across studies. No study made optimal use of theory as recommended in the TCS.

Conclusions The heterogeneity observed and inclusion of pilot designs mean conclusions regarding effectiveness of theory-based interventions targeting older adults prescribed polypharmacy could not be drawn. Further primary research involving theory as a central component of intervention development is required. The review findings will help inform the design of future theory-based adherence interventions.

\section{Key Points}

Theory is rarely used in the development of adherence interventions for older adults prescribed polypharmacy.

Details of exactly how theory informs intervention development are often lacking.

More adherence interventions with a robust theoretical basis are required.

\section{Introduction}

Older adults, aged $\geq 65$ years, commonly suffer from multi-morbidity (i.e. two or more long-term conditions) [1-3]. The treatment of multi-morbid older adults often 
leads to the prescribing of multiple medications, often referred to as polypharmacy $[4,5]$. There is no standard definition of polypharmacy and it is commonly defined using arbitrary cut-off points, such as 'the concomitant use of four or more medications' [5-7].

Adherence is described as 'the extent to which a person's behaviour-taking medication, following a diet, and/or executing lifestyle changes, corresponds with agreed recommendations from a healthcare provider' [8]. Adherence can be challenging for older adults prescribed polypharmacy, with research showing that increases in both the number of prescribed medications and regimen complexity are correlated with lower medication adherence $[8,9]$. Complex regimens are particularly difficult to manage, as they can involve a variety of formulations, multiple daily doses and, in some instances, special administration instructions (e.g. take $1 \mathrm{~h}$ before food) [5, 10, 11]. Cognitive and physiological changes (e.g. swallowing difficulties) that occur with increasing age can also act as barriers to adherence. Non-adherence can be either intentional in nature (i.e. involving a conscious decision-making process) or un-intentional, whereby the patient wants to follow the treatment plan but faces practical difficulties (e.g. forgetfulness) [12]. However, both types of non-adherence can be observed in some patients. Non-adherence rates in older adults range from 25 to $75 \%$ and have been linked to poor clinical outcomes and increases in hospital admissions and healthcare costs [13, 14]. Consequently, improving adherence to long-term medications in this population group is a key international priority for policy makers, researchers and healthcare professionals alike $[8,15,16]$.

To date, interventions that have aimed to improve adherence to prescribed treatments in all patient groups have shown limited effectiveness in improving clinical outcomes and are often too costly or difficult to implement in practice [17]. Several challenges are associated with the design and delivery of adherence interventions. First, the choice of adherence measure selected to demonstrate the effect of the intervention requires careful consideration. A variety of methods are available but no 'gold standard' approach exists. Direct measures (e.g. drug-level monitoring) are seen as evidence that the medication has been consumed but are often time-consuming, expensive and impractical for research purposes. Alternatively, less expensive indirect measures involve some degree of assumption that the patient has consumed the medication, leading to an overestimation of adherence (e.g. self-report) [18-20]. Combining indirect measures has been suggested as one way of overcoming their individual limitations [8]. Adherence measures are used in research to categorise participants as either adherent or non-adherent, for example, an arbitrary cut-off point of consuming more than $80 \%$ of recommended doses is commonly used to categorise participants as adherent [21].

The second challenge with adherence research involves the complexity of the behaviour being targeted as well as the types of interventions developed in an attempt to bring about behaviour change. Complex interventions consisting of 'multiple interacting components' are often selected as the intervention type, but a consistent approach to their development and reporting has been lacking, making evaluation and replication difficult [22]. To assist researchers, the UK Medical Research Council (MRC) produced guidelines that recommend a systematic approach to intervention development and evaluation, with greater emphasis placed on the supporting evidence base and the use of theory (e.g. psychological theories) [22]. One potential explanation for the limited success of previous adherence interventions could be the lack of an explicit theoretical underpinning $[17,23]$. Theory ('a set of concepts, definitions, and propositions that explain or predict ... events or situations by illustrating the relationship between variables') has the potential to assist researchers' understanding of the behaviour change process and guide intervention development and refinement $[24,25]$. For example, theory can assist in the identification of theoretical constructs to target as part of the intervention (e.g. 'self-efficacy') or of participants to include in the study (e.g. patients with low 'self-efficacy') [22, 26, 27]. Theoretical constructs can also be measured pre- and postintervention, allowing researchers to understand the intervention's mechanism of action and to refine the intervention and its underlying theory [27].

Previous reviews of behaviour change interventions that target health behaviours (e.g. HIV prevention) have examined theory use in a more simplistic fashion, by simply comparing interventions that have cited theory with those that did not [28-30]. A recent meta-analysis of medication adherence interventions (delivered to adults aged $>18$ years) examined theory use by simply identifying those that had made reference to a theory or particular intervention approach that is commonly linked to theory (e.g. motivational interviewing [MI]) [30]. This review identified 146 interventions that, overall, produced a modest effect size of 0.294 . Although the authors indicated that this modest effect may have been influenced by poor theory selection, application and operationalisation, they did not undertake a detailed examination of exactly how theory was used to develop or evaluate the interventions. Experts in the field of behaviour change have recognised that the specific way in which theory is used can affect the outcome of the intervention [26, 27]. A theory coding scheme (TCS) has been developed as a method for determining the extent to which interventions are 'theory based' [27]. This research tool allows reviewers to systematically 
identify and reliably describe an intervention's theory base and has been adopted in a number of systematic reviews on behaviour change [26, 27, 31-33].

To date, no review has specifically investigated the use of psychological theories in the design of interventions targeting adherence in older adults prescribed polypharmacy. Therefore, the aim of this review was to determine the overall effectiveness of theory-based interventions on adherence and clinical/humanistic outcomes in older adults prescribed polypharmacy and explore the extent to which psychological theory informed intervention design. As the choice of adherence measure can affect outcomes, this review also examined measures investigated by included studies.

\section{Methods}

\subsection{Protocol}

The methods used in this review followed those established by the Cochrane Collaboration [34]. The protocol can be obtained from the corresponding author upon request. The review findings are reported in line with the PRISMA (Preferred Reporting Items for Systematic Reviews and Meta-Analyses) statement [35].

\subsection{Eligibility Criteria}

Studies were included if they met the relevant criteria specified in the Cochrane Effective Practice and Organisation of Care (EPOC) Review Group's Data Collection Checklist, i.e. randomised controlled trials (RCTs), nonrandomised controlled clinical trials, interrupted time series studies and controlled before-and-after studies [36]. Pilot RCTs were also eligible as there has been encouragement towards the use of theory in intervention design, and studies could potentially be in the preliminary stages of development [22].

Studies were included if the population had a mean (or median) age of at least 65 years and were taking a mean (or median) of four or more medications (i.e. the definition of polypharmacy stated in Sect. 1) [7]. Any type of intervention to improve adherence was considered for inclusion provided the intervention had a comparative control group. Similar to a recent Cochrane review on adherence interventions [17], eligible studies had to include at least one medication adherence outcome and one clinical outcome (e.g. hospitalisations) or humanistic outcome (e.g. healthrelated quality of life [HRQOL]).

Studies were excluded if they did not explicitly state that an established theory (or theoretical framework) underpinned their intervention. Cited theories had to meet the definition proposed by Glanz and Rimer [25], as noted in Sect. 1. Studies focusing on patients with opioid, alcohol or tobacco addictions were excluded from this review as these problems are considerably more severe and generally differ in nature [17, 37].

\subsection{Information Sources/Search}

A search of eight electronic databases (MEDLINE, Embase, PsycINFO, SCOPUS, CINAHL, Web of Science, International Pharmaceutical Abstracts, the Cochrane Library) was conducted. Studies published in the English language, from inception of the database to the search date (March 2015), were considered for inclusion. Variations of the following terms were used in the search strategy and adapted for each database: 'older adults', 'medication adherence', 'polypharmacy' and 'theory' (see MEDLINE search string in Appendix S1 in the Electronic Supplementary Material [ESM]). Reference lists and articles that cited included studies were hand searched. Other sources that were searched are detailed in Appendix S2 in the ESM.

\subsection{Study Selection}

After removal of duplicates, screening of study titles and abstracts was undertaken independently by two reviewers (DP, CR) to identify studies suitable for inclusion. Following this, full-text articles were retrieved and assessed for eligibility. Disagreements were resolved through discussion and by consultation with a third reviewer (CC).

\subsection{Data Collection and Analysis}

A data extraction form was developed and piloted using one of the studies agreed upon for inclusion and refined before it was used to extract data from the remaining studies. Two researchers (DP, CR) independently extracted data using the data extraction form. Any disagreement, for any component of data analysis, was resolved through third-party discussion (CC).

Given the wide variety of outcomes measures and intervention designs commonly reported in adherence interventions, it was anticipated a priori that a meta-analysis would not be feasible [17]. Therefore, an in-depth narrative analysis was chosen to present the review findings. The extent of theory use in each included study was evaluated using pre-defined categories from the TCS [27]. This coding scheme consists of 19 items, each of which falls into at least one of six categories. Categories 1-3 deal with the extent to which the intervention has been based on theory, whereas categories 4-6 relate to theory testing and refinement. The items in each category are detailed in Table 1. 
Table 1 Categories of the theory coding scheme [27]

\begin{tabular}{|c|c|}
\hline TCS category & Relevant items of TCS \\
\hline \multirow[t]{3}{*}{$\begin{array}{l}\text { Category } 1 \text { : Is theory } \\
\text { mentioned? }\end{array}$} & Theory/model of behaviour mentioned (TCS item 1) \\
\hline & $\begin{array}{l}\text { Targeted construct mentioned as predictor of behaviour } \\
\text { (TCS item 2) }\end{array}$ \\
\hline & Intervention based on a single theory (TCS item 3 ) \\
\hline \multirow{7}{*}{$\begin{array}{l}\text { Category } 2 \text { : Are relevant } \\
\text { theoretical constructs targeted } \\
\text { by the intervention? }\end{array}$} & $\begin{array}{l}\text { Targeted construct mentioned as predictor of behaviour } \\
\text { (TCS item 2) }\end{array}$ \\
\hline & $\begin{array}{l}\text { Theory/predictors used to select/develop intervention } \\
\text { techniques (TCS item 5) }\end{array}$ \\
\hline & $\begin{array}{l}\text { Intervention techniques(s) linked to theory-relevant } \\
\text { construct }(s)\end{array}$ \\
\hline & $\begin{array}{l}\text { All intervention techniques are explicitly linked to at } \\
\text { least one theory-relevant construct/predictor (TCS } \\
\text { item 7) }\end{array}$ \\
\hline & $\begin{array}{l}\text { At least one, but not all, of the intervention techniques } \\
\text { are explicitly linked to at least one theory-relevant } \\
\text { construct/predictor (TCS item } 8 \text { ) }\end{array}$ \\
\hline & $\begin{array}{l}\text { Group of techniques are linked to a group of constructs/ } \\
\text { predictors (TCS item 9) }\end{array}$ \\
\hline & $\begin{array}{l}\text { Theory-relevant construct(s) linked to intervention } \\
\text { techniques }(s)\end{array}$ \\
\hline
\end{tabular}

Category 3: Is theory used to select intervention recipients or tailor interventions?

Category 4: Are the relevant theoretical constructs measured?
All theory-relevant constructs/predictors are explicitly linked to at least one intervention technique (TCS item 10)

At least one, but not all, of the theory relevant constructs/predictors are explicitly linked to at least one intervention technique (TCS item 11)

Description

Models/theories that specify relations among variables to explain or predict behaviour are mentioned, even if the intervention is not based on this theory ${ }^{\mathrm{a}}$

Evidence that the psychological construct relates to (correlates/predicts/causes) behaviour should be presented within the introduction or method ${ }^{\mathrm{a}}$

The intervention is based on a single theory (rather than a combination of theories or predictors) ${ }^{\mathrm{a}}$

See above

The intervention is explicitly based on a theory or predictor or combination of theories or predictors ${ }^{\mathrm{a}}$

Each intervention technique is explicitly linked to at least one theory-relevant construct/predictor ${ }^{\mathrm{a}}$

At least one, but not all, of the intervention techniques are explicitly linked to at least one theory-relevant construct/ predictor $^{\mathrm{a}}$

A cluster of techniques is linked to a cluster of constructs/ predictors $^{\mathrm{a}}$

Every theoretical construct within a stated theory, or every stated predictor (see item 5), is linked to at least one intervention technique ${ }^{\mathrm{a}}$

At least one, but not all, of the theoretical constructs within a stated theory or at least one, but not all, of the stated predictors (see item 5) are linked to at least one intervention technique ${ }^{\mathrm{a}}$

Theory/predictors used to select recipients for the intervention (TCS item 4)

Theory/predictors used to tailor intervention techniques to recipients (TCS item 6)

Theory-relevant constructs/predictors are measured (TCS item 12)

Participants were screened/selected based on achieving a particular score/level on a theory-relevant construct/ predictor $^{\mathrm{a}}$

The intervention differs for different sub-groups that vary on a psychological construct (e.g. stage of change) or predictor at baseline ${ }^{\mathrm{a}}$

At least one construct of theory (or predictor) mentioned in relation to the intervention is measured post-intervention

At least one construct of theory (or predictor) mentioned in relation to the intervention is measured pre- and postintervention $^{\mathrm{a}}$

All of the measures of theory-relevant constructs/predictors had some evidence for their reliability

At least one, but not all, of the measures of theory relevant constructs/predictors had some evidence for their reliability

All of the measures of theory relevant constructs/predictors have been previously validated

At least one, but not all, of the measures of theory relevant constructs/predictors have been previously validated

The behaviour measure had some evidence for its reliability

The behaviour measure has been previously validated ${ }^{\mathrm{a}}$ 
Table 1 continued

\begin{tabular}{|c|c|c|}
\hline TCS category & Relevant items of TCS & Description \\
\hline \multirow[t]{10}{*}{ Category $5:$ Is theory tested? } & $\begin{array}{l}\text { Theory relevant constructs/predictors are measured } \\
\text { (TCS item 12) }\end{array}$ & See above \\
\hline & Quality of measures (TCS item 13) & See above \\
\hline & \multirow{4}{*}{$\begin{array}{l}\text { Randomization of participants to condition (TCS item } \\
\text { 14) }\end{array}$} & Do the authors claim randomization? \\
\hline & & $\begin{array}{l}\text { Is a method of random allocation to condition described } \\
\text { (e.g. random number generator)? }\end{array}$ \\
\hline & & Was the success of randomization tested? \\
\hline & & $\begin{array}{l}\text { Was the randomization successful (or baseline differences } \\
\text { between intervention and control group statistically } \\
\text { controlled)? }\end{array}$ \\
\hline & $\begin{array}{l}\text { Changes in measured theory-relevant constructs/ } \\
\text { predictors (TCS item 15) }\end{array}$ & $\begin{array}{l}\text { The intervention leads to significant change in at least one } \\
\text { theory-relevant construct/predictor (vs. control group) in } \\
\text { favour of the intervention }^{\text {a }}\end{array}$ \\
\hline & $\begin{array}{l}\text { Meditational analysis of constructs/predictors (TCS } \\
\text { item 16) }\end{array}$ & $\begin{array}{l}\text { Any evidence of hypothesized mediating variable or change } \\
\text { in hypothesized mediating variable predicting } \\
\text { independent variable }\end{array}$ \\
\hline & Results discussed in relation to theory (TCS item 17) & $\begin{array}{l}\text { Results are discussed in terms of the theoretical basis of the } \\
\text { intervention }^{b}\end{array}$ \\
\hline & Appropriate support for theory (TCS item 18) & $\begin{array}{l}\text { Support for the theory is based on appropriate mediation } \\
\text { OR refutation of the theory is based on obtaining } \\
\text { appropriate null effects (i.e. changing behaviour without } \\
\text { changing the theory-relevant constructs) }\end{array}$ \\
\hline Category 6: Is theory refined? & Results used to refine theory (TCS item 19) & $\begin{array}{l}\text { The authors attempt to refine the theory upon which the } \\
\text { intervention was based by either (1) adding or removing } \\
\text { constructs to the theory, or (2) specifying that the } \\
\text { interrelationships between the theoretical constructs } \\
\text { should be changed and spelling out which relationships } \\
\text { should be changed }^{\text {a }}\end{array}$ \\
\hline
\end{tabular}

TCS theory coding scheme

${ }^{\text {a }}$ Explanation reproduced from the original TCS paper by Michie and Prestwich [27]

${ }^{\mathrm{b}}$ Explanation reproduced from Farmer et al. [31]

\subsection{Risk of Bias of Individual Studies}

The reviewers (DP, CR) conducted independent risk-ofbias assessments using tools developed by the Cochrane Collaboration ('risk of bias' tool for randomised studies and 'suggested risk of bias criteria for EPOC reviews' for non-randomised studies) $[34,36]$. Studies were assigned an overall rating of low, high or unclear risk.

\section{Results}

\subsection{Study Selection}

The electronic searches identified 4366 citations, and hand searching identified a further 33 citations. Following title and abstract screening, 76 full-text articles were retrieved and reviewed for eligibility of inclusion. Five studies met the inclusion criteria: one RCT [38] and four pilot RCTs [39-42] (Fig. 1).

\subsection{Study Characteristics}

As expected, the included studies were heterogeneous in terms of outcome measures, targeted clinical conditions and psychological theories underpinning intervention design. In addition, four of the studies were pilot RCTs with small sample sizes. Therefore, a narrative summary is provided that outlines how each study reported the use of theory during intervention development. Outcome data have been summarised to give an indication of preliminary findings [43].

A total of 2294 participants were recruited across all five studies (range 15-2097). The mean age of participants ranged from 67 to 78 years, and the mean number of regularly prescribed medications ranged from 5.5 to 11.25 medications. Four studies targeted individual clinical conditions (hypertension [40], osteoporosis [38], heart failure [39], stroke [42]), and one study focused on co-existing conditions (diabetes and chronic kidney disease) [41]. Although the study populations were prescribed a mean of 
Fig. 1 PRISMA flow diagram of the systematic review process. ${ }^{1}$ Authors were contacted in both instances with no response

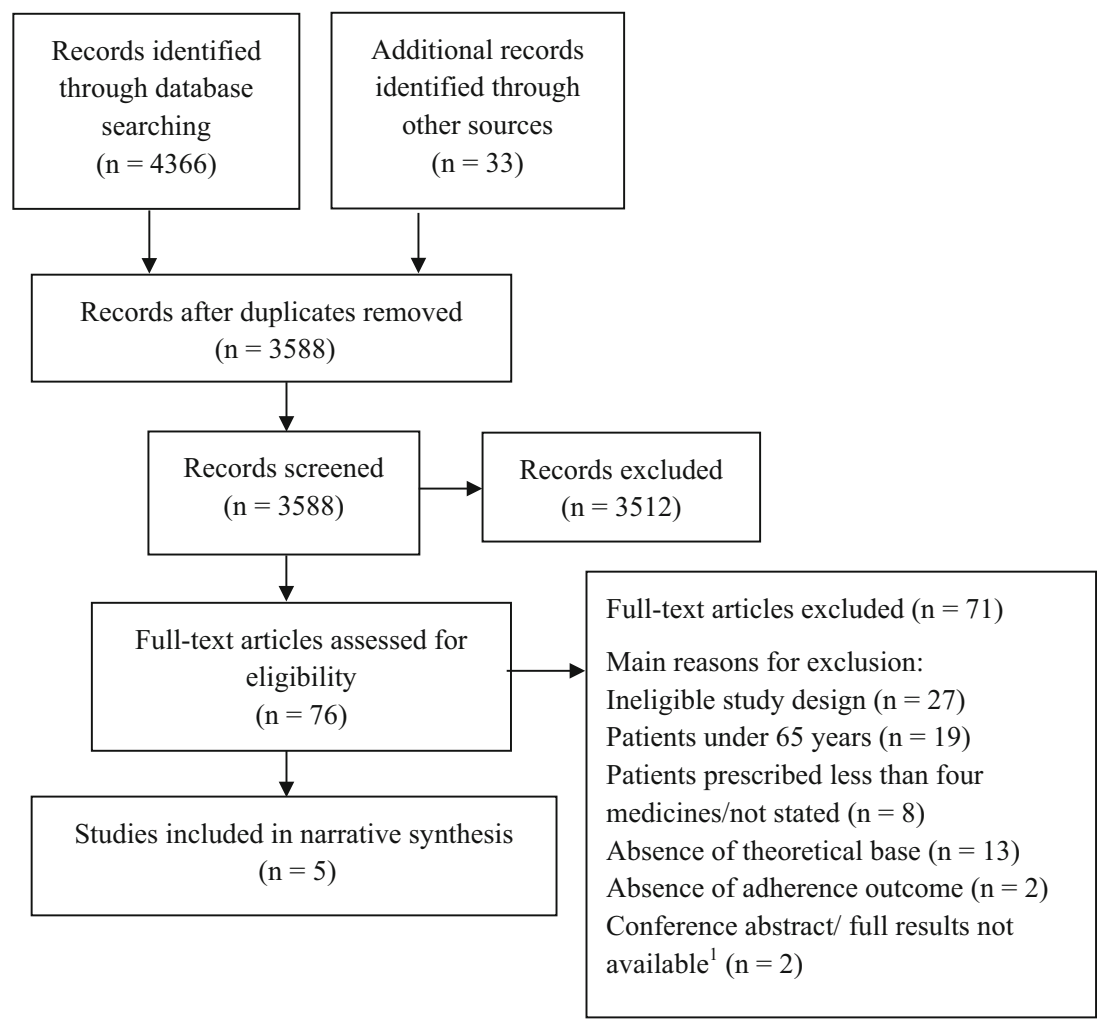

four or more medications, only two studies measured adherence to all prescribed medications [39, 41]; the other studies measured adherence to a group of medications used to treat the particular condition that was the intervention target [40, 42, 44]. Four studies used a cut-off point to classify patients as adherent using self-report scores, pill counts or electronic monitoring [38-40, 42]. Two studies specifically recruited patients who were classified as nonadherent [40, 42].

All of the interventions were complex in nature and included a range of educational and behavioural techniques, such as self-monitoring [41], prompts [40], feedback [40] and MI [38, 41]. Intervention participants received between one and eight sessions, ranging from 2 to $89 \mathrm{~min}$ in duration. Participants were followed-up for various time periods, from 3 to 12 months. Adherence measures varied across studies, with three studies relying on a single measure [38-40]. These included self-report [39, 41, 45, 46], medication possession ratios (MPRs) calculated using pharmacy dispensing records [38], pill counts [41] and electronic monitoring using medication event monitoring systems (MEMS) [40]. The clinical outcomes measured depended on the clinical condition targeted, for example, a change in blood pressure (hypertension) [40] and self-reported falls and fractures (osteoporosis) [38]. Two studies also measured humanistic outcomes (e.g. HRQOL) [38, 39, 47]. A summary of the characteristics of included studies is provided in Table 2.

\subsection{Theoretical Underpinning of Included Studies}

All of the included studies were originally based on a single theory, although O'Carroll et al. [42] also made reference to a separate related theory in a linked publication [48] regarding a process evaluation; this is discussed in more detail below (Sect. 3.3.2). The majority of included studies in this review were small-scale pilot studies, and only one study reported testing the underpinning theory [48]. None of the authors reported theory refinement based on the study results. Consequently, we decided to focus solely on categories 1-3 of the TCS for the purposes of this in-depth narrative review, as these categories explore how the researchers have used theory in developing their interventions. A summary of the main findings from this narrative analysis can be found in Table 3. An overall judgement of 'yes', 'no' or 'partially' was made for each TCS category based on whether the study met all, none or some of the relevant TCS items (see Table 3).

\subsubsection{Social Cognitive Theory}

Barnason et al. [39] based their intervention on social cognitive theory (SCT) (TCS category 1: yes) [24, 49]. The intervention consisted of counselling and education and was delivered to patients with heart failure (HF) upon transition from secondary to primary care. SCT helps to understand human thought and behaviour and includes a 


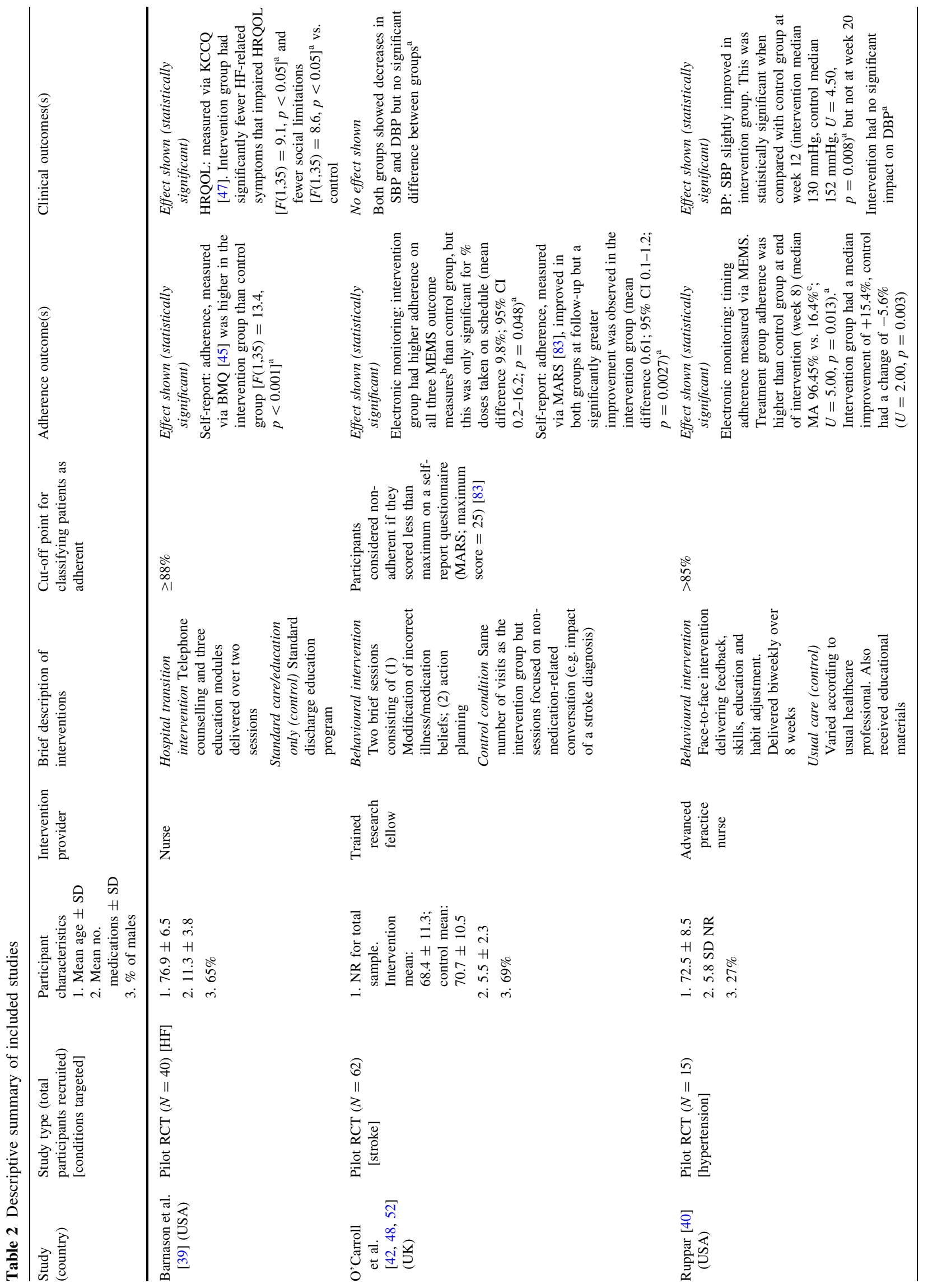




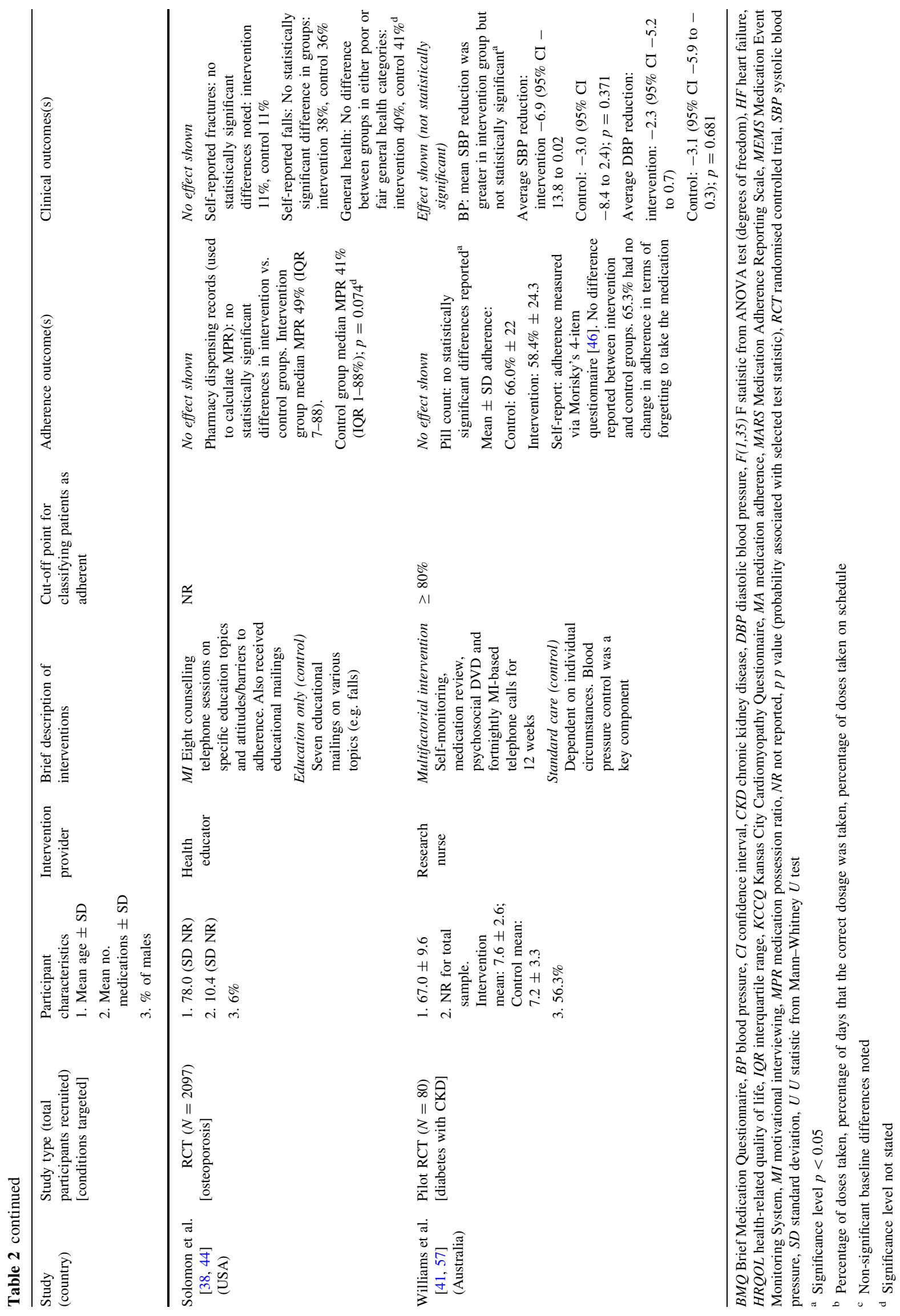


Table 3 A summary of the narrative analysis for included studies based on categories 1-3 of the theory coding scheme [27]

\begin{tabular}{|c|c|c|c|c|c|c|}
\hline \multirow[t]{2}{*}{$\begin{array}{l}\text { Study } \\
\text { (country) }\end{array}$} & \multicolumn{2}{|c|}{$\begin{array}{l}\text { Category } 1: \text { Is theory } \\
\text { mentioned? }\end{array}$} & \multicolumn{2}{|c|}{$\begin{array}{l}\text { Category } 2 \text { : Are relevant theoretical constructs } \\
\text { targeted by the intervention? }\end{array}$} & \multicolumn{2}{|c|}{$\begin{array}{l}\text { Category } 3 \text { : Is theory used to tailor the } \\
\text { intervention or select the intervention } \\
\text { recipients? }\end{array}$} \\
\hline & $\begin{array}{l}\text { Yes, no, } \\
\text { or } \\
\text { partially }^{\mathrm{a}}\end{array}$ & Reason & $\begin{array}{l}\text { Yes, no, } \\
\text { or } \\
\text { partially }^{\mathrm{b}}\end{array}$ & Reason & $\begin{array}{l}\text { Yes, no, } \\
\text { or } \\
\text { partially }^{c}\end{array}$ & Reason \\
\hline $\begin{array}{l}\text { Barnason } \\
\text { et al. [39] } \\
\text { (USA) }\end{array}$ & $\mathrm{Yes}^{\mathrm{a}}$ & $\begin{array}{l}\text { Met TCS item } 1 \\
\text { and } 3 \\
\text { Bandura's } \\
\text { SCT } \\
\text { Met TCS item } 2 \\
\text { Refer to } \\
\text { category } 2\end{array}$ & Yes $^{b}$ & $\begin{array}{l}\text { Met TCS item } 2 \text { Targeted constructs of } \\
\text { SCT (e.g. self-regulation) were } \\
\text { mentioned as predictors of adherence } \\
\text { Met TCS item } 5 \text { Theory was used to select } \\
\text { intervention techniques (e.g. self- } \\
\text { monitoring selected based on self- } \\
\text { regulation construct of SCT) } \\
\text { Met TCS item } 7 \text { All intervention } \\
\text { techniques were linked to theoretical } \\
\text { constructs or predictors (e.g. verbal } \\
\text { persuasion technique linked to self- } \\
\text { efficacy) } \\
\text { Met TCS item } 10 \text { Targeted constructs } \\
\text { were linked explicitly to at least one } \\
\text { intervention technique }\end{array}$ & Partially $^{\mathrm{c}}$ & $\begin{array}{l}\text { Met TCS item } 6 \text { Predictors } \\
\text { (e.g. motivation) were } \\
\text { examined via } \\
\text { questionnaires and used to } \\
\text { tailor the intervention to } \\
\text { individual patients } \\
\text { Did not meet TCS item } 4 \\
\text { Intervention recipients } \\
\text { were not selected using } \\
\text { theory (e.g. based on } \\
\text { 'self-efficacy' levels) }\end{array}$ \\
\hline $\begin{array}{l}\text { O'Carroll } \\
\text { et al. } \\
{[42,48,52]} \\
\text { (UK) }\end{array}$ & Yes $^{\mathrm{a}}$ & $\begin{array}{l}\text { Met TCS items } 1 \\
\text { and } 3 \\
\text { Leventhal's } \\
\text { SRM (also } \\
\text { made } \\
\text { reference to } \\
\text { Hall and } \\
\text { Fong's } \\
\text { temporal self- } \\
\text { regulation } \\
\text { theory) } \\
\text { Met TCS item } 2 \\
\text { Refer to } \\
\text { category } 2\end{array}$ & Yes $^{\mathrm{b}}$ & $\begin{array}{l}\text { Met TCS item } 2 \text { Targeted construct of } \\
\text { SRM ('illness perceptions') was } \\
\text { mentioned as a predictor of adherence } \\
\text { Met TCS item } 5 \text { Theory was used to select } \\
\text { intervention techniques } \\
\text { Met TCS item } 7 \text { All intervention } \\
\text { techniques were linked to theoretical } \\
\text { constructs/predictors (e.g. information } \\
\text { about health consequences was linked to } \\
\text { illness perceptions) } \\
\text { Met TCS item } 11 \text { Targeted constructs/ } \\
\text { predictors were linked explicitly to at } \\
\text { least one intervention technique }\end{array}$ & $\mathrm{No}^{\mathrm{c}}$ & $\begin{array}{l}\text { Did not meet TCS item } 6 \\
\text { Intervention was not } \\
\text { tailored based on theory } \\
\text { Did not meet TCS item } 4 \\
\text { Intervention recipients } \\
\text { were selected based on a } \\
\text { self-report questionnaire } \\
\text { score but not specifically } \\
\text { using theory (e.g. based } \\
\text { on illness perceptions) }\end{array}$ \\
\hline $\begin{array}{l}\text { Ruppar }[40] \\
\text { (USA) }\end{array}$ & Yes $^{\mathrm{a}}$ & $\begin{array}{l}\text { Met TCS item } 1 \\
\text { and } 3 \\
\text { Leventhal's } \\
\text { SRM } \\
\text { Met TCS item } 2 \\
\text { Refer to } \\
\text { category } 2\end{array}$ & Partially ${ }^{\mathrm{b}}$ & $\begin{array}{l}\text { Met TCS item } 2 \text { Targeted construct } \\
\text { (illness perceptions) was mentioned as a } \\
\text { predictor of adherence behaviour } \\
\text { Did not meet TCS item } 5 \text { Theory was not } \\
\text { used to select all intervention techniques } \\
\text { (e.g. prompts) } \\
\text { Met TCS item } 8 \text { At least one, but not all, } \\
\text { intervention techniques were explicitly } \\
\text { linked to theoretical constructs (e.g. } \\
\text { habit modification not linked to theory) } \\
\text { Met TCS item } 11 \text { Key theoretical } \\
\text { construct (illness perceptions) was } \\
\text { linked to intervention techniques }\end{array}$ & $\mathrm{No}^{\mathrm{c}}$ & $\begin{array}{l}\text { Did not meet TCS item } 6 \\
\text { Habit modification was } \\
\text { tailored but not linked to } \\
\text { theory } \\
\text { Did not meet TCS item } 4 \\
\text { Intervention recipients } \\
\text { were not selected using } \\
\text { theory (e.g. based on their } \\
\text { illness perceptions) }\end{array}$ \\
\hline
\end{tabular}


Table 3 continued

\begin{tabular}{|c|c|c|c|c|c|c|}
\hline \multirow[t]{2}{*}{$\begin{array}{l}\text { Study } \\
\text { (country) }\end{array}$} & \multicolumn{2}{|c|}{$\begin{array}{l}\text { Category } 1: \text { Is theory } \\
\text { mentioned? }\end{array}$} & \multicolumn{2}{|c|}{$\begin{array}{l}\text { Category } 2 \text { : Are relevant theoretical constructs } \\
\text { targeted by the intervention? }\end{array}$} & \multicolumn{2}{|c|}{$\begin{array}{l}\text { Category } 3 \text { : Is theory used to tailor the } \\
\text { intervention or select the intervention } \\
\text { recipients? }\end{array}$} \\
\hline & $\begin{array}{l}\text { Yes, no, } \\
\text { or } \\
\text { partially }\end{array}$ & Reason & $\begin{array}{l}\text { Yes, no, } \\
\text { or } \\
\text { partially }\end{array}$ & Reason & $\begin{array}{l}\text { Yes, no, } \\
\text { or } \\
\text { partially }^{\mathrm{c}}\end{array}$ & Reason \\
\hline $\begin{array}{l}\text { Solomon et al. } \\
{[38,44]} \\
\text { (USA) }\end{array}$ & Partially $^{\mathrm{a}}$ & $\begin{array}{l}\text { Met TCS item } 1 \\
\text { and } 3 \\
\text { Prochaska's } \\
\text { TTM } \\
\text { Did not meet } \\
\text { TCS item } 2 \\
\text { Refer to } \\
\text { category } 2\end{array}$ & $\mathrm{No}^{\mathrm{b}}$ & $\begin{array}{l}\text { Did not meet TCS item } 2 \text { The authors did } \\
\text { not explicitly indicate that the } \\
\text { constructs of TTM (e.g. stage of change, } \\
\text { process of change, self-efficacy) were } \\
\text { predictors of adherence } \\
\text { Did not meet TCS item } 5 \text { Theory did not } \\
\text { appear to guide the selection of MI } \\
\text { techniques. MI techniques appear to } \\
\text { have been selected based on similar } \\
\text { interventions and then linked back to } \\
\text { theory } \\
\text { Did not meet TCS item } 7,8 \text { or } 9 \text { MI } \\
\text { techniques were not directly linked back } \\
\text { to constructs within the model } \\
\text { Did not meet TCS item } 10 \text { or } 11 \text { Key } \\
\text { constructs of TTM were not explicitly } \\
\text { linked to MI techniques }\end{array}$ & $\mathrm{No}^{\mathrm{c}}$ & $\begin{array}{l}\text { Did not meet TCS item } 6 \\
\text { The authors did report } \\
\text { that MI is based on an } \\
\text { 'individual's readiness for } \\
\text { change', but they did not } \\
\text { link this to their own } \\
\text { intervention } \\
\text { Did not meet TCS item } 4 \\
\text { Intervention recipients } \\
\text { were not selected using } \\
\text { theory (e.g. based on their } \\
\text { 'stage of change') }\end{array}$ \\
\hline $\begin{array}{l}\text { Williams et al. } \\
{[41,57]} \\
\text { (Australia) }\end{array}$ & $\mathrm{Yes}^{\mathrm{a}}$ & $\begin{array}{l}\text { Met TCS item } 1 \\
\text { and } 3 \mathrm{HBM} \\
\text { (modified) } \\
\text { Met TCS item } 2 \\
\text { Refer to } \\
\text { category } 2\end{array}$ & Partially $^{\mathrm{b}}$ & $\begin{array}{l}\text { Met TCS item } 2 \text { Targeted constructs of the } \\
\text { modified HBM were mentioned as } \\
\text { predictors of adherence (e.g. self- } \\
\text { efficacy) } \\
\text { Did not meet TCS item } 5 \text { Theory was not } \\
\text { used to select all intervention techniques } \\
\text { (e.g. self-monitoring) } \\
\text { Met TCS item } 8 \text { At least one, but not all, } \\
\text { intervention techniques were explicitly } \\
\text { linked to theoretical constructs (e.g. } \\
\text { goal setting was not linked to } \\
\text { constructs) } \\
\text { Did not meet TCS item } 10 \text { or } 11 \\
\text { Theoretical constructs were not } \\
\text { explicitly linked to intervention } \\
\text { techniques }\end{array}$ & $\mathrm{No}^{\mathrm{c}}$ & $\begin{array}{l}\text { Did not meet TCS item } 6 \mathrm{MI} \\
\text { was tailored but not } \\
\text { linked to theory. Other } \\
\text { intervention techniques } \\
\text { were not tailored } \\
\text { Did not meet TCS item } 4 \\
\text { Intervention recipients } \\
\text { were not selected using } \\
\text { theory (e.g. based on their } \\
\text { level of 'self-efficacy') }\end{array}$ \\
\hline
\end{tabular}

$H B M$ health belief model, $M I$ motivational interviewing, SCT social cognitive theory, SRM Self-Regulation Model, TCS theory coding scheme, TTM transtheoretical model

a Judgement of 'yes' if study met TCS items 1, 2 and 3 in category 1. Judgement of 'partially' if study met any of the TCS items in category 1. Judgement of 'no' if study did not meet any TCS items in category 1

b Judgement of 'yes' if study met TCS items 2 and 5 and 7, 8 or 9 and 10 or 11 in category 2. Judgement of 'partially' if study met any of the TCS items in category 2. Judgement of 'no' if study did not meet any TCS items in category 2

c Judgement of 'yes' if study met TCS items 4 and 6 in category 3. Judgement of 'partially' if study met any of the TCS items in category 3. Judgement of 'no' if study did not met any TCS items in category 3

core reciprocal model whereby personal, behavioural and environmental factors influence each other. The authors indicated that personal factors (e.g. motivation) and environmental factors (e.g. assistance from others) impacted on the behaviour. Key constructs in this model are 'self-efficacy' and 'self-regulation', and these were linked to intervention techniques such as verbal persuasion and selfmonitoring, respectively (TCS category 2: yes). Some techniques were also linked to the medication adherence conceptual framework, which was used alongside the theoretical basis to guide intervention design. This conceptual framework, developed based on a literature review, links closely with SCT and focuses on 'the relationship between environmental factors, patient characteristics, and medication adherence as a process that ultimately affects patient outcomes' in older adults with HF [50]. SCT was not used 
to select patients for inclusion in the trial but was used to tailor the intervention based on an initial assessment of personal factors (e.g. participants with low motivation were given tailored information on the benefits of adherence) (TCS category 3: partially). This intervention was tested in a pilot study and led to statistically significant differences in both self-reported adherence and HRQOL (see Table 2).

\subsubsection{Self-Regulation Model}

Leventhal's Self-Regulation Model (SRM) [24, 51] was cited as the basis for intervention development in two of the included studies [40, 42]. First, SRM was cited by Ruppar [40] as the basis of an intervention that aimed to improve adherence to medicines prescribed for hypertension (TCS category 1: yes). SRM consists of three constructs: (1) 'illness perceptions' (i.e. the beliefs a person holds about their illness), (2) 'coping responses'/action planning, (3) 'appraisal'/monitoring of responses [51]. The key construct in this model, 'illness perceptions', consists of both cognitive perceptions (e.g. identity/illness label and symptoms, cause, timeline, consequences and curability/controllability) and emotional perceptions (e.g. anxiety, depression, fear). In Ruppar's study [40], SRM was discussed in terms of how it related to hypertension, as these patients are commonly asymptomatic, in contrast to other conditions, where symptoms act as feedback that medication doses have been missed (e.g. Parkinson's disease). The author proposed that a lack of feedback from 'perceived symptoms' was a possible predictor of non-adherence. To account for the lack of symptom feedback, the intervention was based on feedback gained from blood pressure monitoring and medication-taking behaviour. Education on health consequences of poorly controlled hypertension was also linked to the 'illness perceptions' construct (i.e. 'consequences' dimension). However, other techniques, such as habit analysis and prompts, were not explicitly linked to theory (TCS category 2: partially). Participants were not selected based on theory, nor was theory used to tailor the intervention (TCS category 3: no). This pilot study reported a statistically significant difference in medication adherence between intervention and control at the end of the intervention period (week 8). A significant decrease in systolic blood pressure (SBP) was noted at week 12 for the intervention group, but SBP increased slightly again at week 20 (see Table 2).

O'Carroll et al. [42, 52] also cited Leventhal's SRM as the underpinning theory for an intervention that aimed to improve adherence in stroke survivors (TCS category 1: yes). The authors indicated that the two main intervention components, modification of incorrect medication/illness beliefs and action planning, would target intentional and unintentional non-adherence, respectively. The first intervention component was linked to the illness perceptions' construct of SRM. The second component was linked to a predictor of medication adherence that had been demonstrated in previous research (i.e. forgetfulness due to cognitive impairment) [52]. In a process evaluation paper, O'Carroll et al. [48] also made reference to a newer selfregulation theory posed by Hall and Fong (temporal selfregulation theory [TST]) [53]. TST incorporates a theoretical construct termed 'behavioural pre-potency' ('presence of cues to action in the environment'), which the authors linked to the action planning component (TCS category 2: yes). Theory was not used to select intervention recipients or tailor the intervention (TCS category 3: no). This study led to improvements in objectively measured adherence via MEMs, but this was only statistically significant for the percentage of doses taken on schedule. Both groups reported higher self-reported adherence at followup, and this was significantly greater in the intervention group. There were no statistically significant differences in changes to blood pressure between groups (see Table 2).

\subsubsection{Transtheoretical Model of Behaviour Change}

Solomon et al. [38, 44] used MI as the basis of their telephone intervention to improve adherence to medications prescribed for osteoporosis. The transtheoretical model (TTM) of behaviour change (also known as the stages of change model) was cited as the underpinning theory for MI [54]. TTM consists of multiple constructs: 'stages of change', 'process of change', 'self-efficacy', 'temptation' and 'decisional balance'. The 'stages of change' construct consists of five sequential stages: pre-contemplation, contemplation, preparation, action and maintenance [24]. It appears that the authors selected MI based on success in previous adherence studies and then linked the approach to the TTM (TCS category 1: partially) [24, 54-56]. The authors discussed MI in general, indicating that it makes use of active listening and relationship building to allow participants to evaluate risks and treatment options, but they did not make explicit links between their intervention and relevant theoretical constructs (TCS category 2: no). The authors did not appear to use theory to select participants or report whether the intervention was tailored based on theory (TCS category 3: no). Statistically significant improvements in medication adherence, changes in selfreported falls, fractures or general health were not reported (see Table 2).

\subsubsection{Health Belief Model}

A modified version of the health belief model (HBM) was cited by Williams et al. [41, 57] as the basis for a multicomponent behavioural and educational intervention 
Fig. 2 Risk of bias summary for the five included studies. Asterisk denotes other potential sources of bias included bias relating specifically to adherence studies, for example, self-report bias

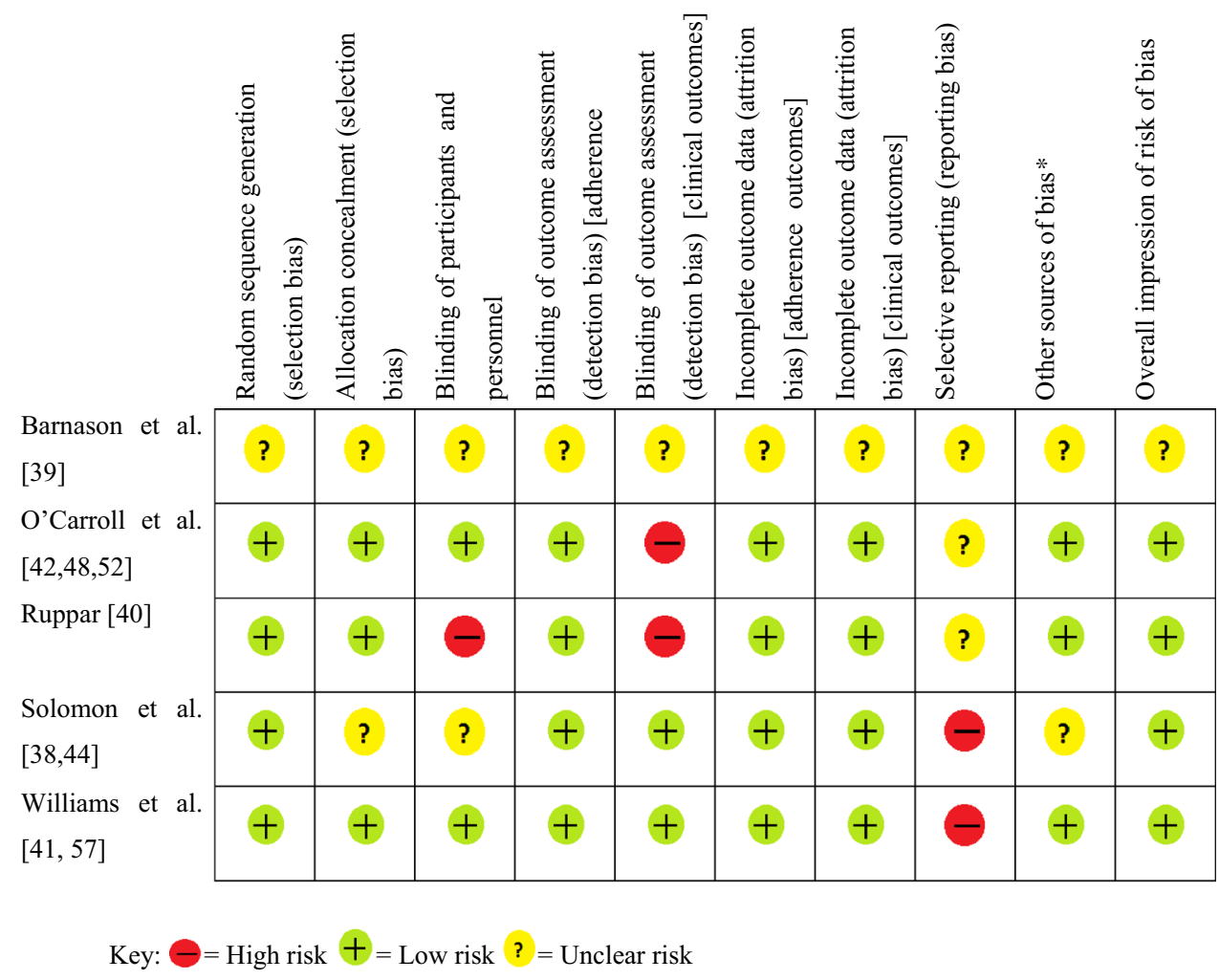

\subsection{Risk of Bias of Individual Studies}

The risk of bias summary, displayed in Fig. 2, gives an overview of the quality of included studies. An overall assessment of low risk of bias was judged for four studies $[38,40-42]$ and an unclear risk for the fifth [39].

\section{Discussion}

This is the first systematic review to provide an in-depth examination of theory-based adherence interventions targeting older adults who are prescribed polypharmacy. It differs from other reviews as it has examined in detail the extent to which theory was used in intervention development $[17,30,61-63]$.

\subsection{Adherence and Clinical Outcomes}

The type of adherence measure varied across studies, and only two studies [41, 42] followed recommendations to employ multiple measures [8]. At present, there is no consensus or guidance on how best to measure adherence to multiple medications. A daily polypharmacy possession ratio has been proposed as a method to calculate adherence using pharmacy dispensing data but requires further validation [64]. To allow adherence research to advance 
further, it is essential that robust methods of measuring adherence to polypharmacy are developed and tested.

Only one study considered the impact of polypharmacy on medication adherence and discussed the associated challenges [41]. Reasons for non-adherence can vary depending on the prescribed regimens and patients' associated beliefs. This has important implications for adherence research, as a 'one-size-fits-all' intervention is unlikely to benefit all patients. Consideration should be given to how theory can be used to tailor the components of complex interventions to individual patient's needs. Studies that include participants who are classified as highly adherent may find it difficult to demonstrate a significant effect as there is limited scope for improvement ('ceiling effect') [17, 40]. Future interventions need to specifically target patients who are non-adherent at baseline.

The variety of clinical outcomes measured by included studies reflects the range of clinical conditions targeted. For studies that aim to target multi-morbid patients, generic humanistic outcomes, such as HRQOL or healthcare utilisation measures, may be more appropriate as opposed to condition-specific clinical outcomes [17]. The development of a core outcome set ('an agreed standardized collection of outcomes ... which should be measured and reported, as a minimum, in all trials for a specific clinical area') would aid comparisons of interventions targeting multi-morbid patients prescribed polypharmacy [65].

\subsection{Intervention Effectiveness}

Pilot studies, which the MRC recommends should be part of the preliminary evaluation of complex interventions, are described as 'a version of the main study that is run in miniature to test whether the components of the main study can all work together' [66]. Although not powered to test for significance, all of the included pilot studies used some form of hypothesis testing, with three describing the positive effects shown as significant [39, 40, 42]. Results from pilot studies are not always reported, and many fail to advance to definitive trials. On the one hand, it is possible that a significant effect may be missed in an underpowered pilot study; conversely, there is also the chance of observing the opposite effect in a larger definitive trial [67]. Consequently, the results of pilot studies should be interpreted with caution. This limitation was recognised by Williams et al. [41], whose pilot study failed to show significant effects. Although conclusions on the overall effectiveness of theory-based studies cannot be drawn from this review, the findings from the included studies are a stepping stone in the advancement of the application of theory in designing interventions $[43,66]$.

\subsection{Theoretical Basis}

Overall, few studies cited theory as a basis for their intervention, and only one reported theory testing based on study outcomes [48]. An in-depth analysis using categories 1-3 of the TCS indicated that the selection of intervention components was not always guided by theory or was not reported as such. Both studies that included MI did not outline exactly how the key constructs of the cited theory explicitly linked to MI techniques [56, 68]. MI was not originally developed from a single theory, and although some researchers have attempted to link it to various theories (e.g. TTM, SCT), the mechanisms through which it facilitates behaviour change remain unclear [69]. Solomon et al. [38] described MI as a method that was 'built upon Prochaska's transtheoretical model of behaviour change' but did not make explicit links between theory and their adherence intervention. This lack of theoretical understanding may be reflected in the design of this MI-based intervention and the subsequent outcome. The other four studies employed a more theory-driven approach whereby theory guided the selection of intervention techniques [39-42]. However, in two of these studies, not all techniques were linked to theory $[40,41]$. It is evident from the analysis that theory could be utilised further, either in recruiting participants or in tailoring the intervention to their needs based on theoretical constructs. For example, Barnason et al. [39] measured relevant theoretical constructs/predictors (e.g. motivation) and used these to tailor the intervention to participants; this approach may have influenced the positive effect seen. O'Carroll et al. [48] have provided a useful example of how theory can be used to explore the intervention's mechanism of action in a theory-based process evaluation.

All five interventions targeted the same behaviour (adherence) but were based on a range of different psychological theories. With such a wide range of theories available in the literature, selecting just one can be a difficult task. As a result, theory selection is commonly based on experience, personal preference or what is 'in fashion' [23]. When selecting theory it is important to provide a clear rationale; however, none of the study authors clearly outlined their choice. However, it is possible that the authors gave theory selection due consideration but did not report this. Selecting the most appropriate theory can also be challenging in instances where individual theories do not cover all potential influences on the target behaviour. Failure to consider all potentially relevant psychological processes, such as non-reflective processes, may have placed limitations on the types of techniques developed. For example, SCT does not consider the role that habit has to play in medication taking [49]. 
To overcome the above challenges in theory selection for behaviour change intervention development, a group of health service researchers and health psychologists have devised the theoretical domains framework (TDF), which encompasses constructs from 33 behaviour change theories, including those cited by studies in this review [70, 71]. This consolidation of theories was recently supported by Holmes et al. [63] in a systematic review that investigated the application of four theories in observational and experimental adherence research. A behavioural analysis via quantitative or qualitative methods, using the TDF, can aid the selection of 'key influences' (theoretical domains) that can be targeted to elicit behaviour change [70]. These 'key influences' can then be explicitly linked to the most appropriate behaviour change techniques (BCTs) ('the smallest components of behaviour change interventions that on their own in favourable circumstances can bring about change'), for example, goal setting and prompts/cues $[25,27,72-74]$. A change in 'key influences' will, in theory, lead to behaviour change [23]. Although the TDF was originally developed in 2005 , it has only gained significant attention in the field of adherence research in recent years, so it is unsurprising that the five included studies did not make reference to this $[75,76]$.

The findings from studies in the current review $(n=5)$ demonstrate that, even when cited, theory appears to be under-utilised when designing interventions. Further research needs to be conducted to draw definitive conclusions regarding the effectiveness of theory-based interventions that aim to improve adherence in older adults prescribed polypharmacy. Other reviews of theory-based interventions targeting health-related behaviours (e.g. physical activity, diabetes self-management) have shown some marginally positive effects, but-in common with this review-they identified an overall under-utilisation of theory [26, 77, 78]. A recent review that looked specifically at text messaging and medication-use monitoring interventions to promote adherence in patients with type 2 diabetes mellitus (in all age groups) showed that only 4 of 11 trials stated an underlying theory [31]. The review authors also used the TCS, but they did not go beyond identifying the number of studies that met each TCS item and the specific theory on which each intervention was based. In contrast, the current review provides an additional in-depth narrative discussion of each intervention, which will inform the development of future theory-based adherence interventions.

As Michie et al. [23] highlight, using an explicit theory does not guarantee the intervention will be effective. It has been proposed that, for theory to influence intervention effectiveness, it must form a key component of rigorous and systematic intervention development [26, 27]. It is important to note that the use of theory in intervention design is based primarily on principle and therefore more empirical research is required to determine whether appropriate use of theory does, in fact, lead to more effective interventions [79]. A review by George et al. [80] has presented findings from non-theory-based adherence interventions $(n=8)$ delivered to older adults prescribed polypharmacy. Effective interventions in this review $(n=4)$ were resource intensive and had no common components. Without a theoretical understanding of the interventions' mechanism of action, it is impossible to decipher the essential ingredients that led to behaviour change. The use of a theoretical basis has the potential to advance the field of adherence research. Even if theorybased interventions fail to produce a positive effect, they can still be used to develop an understanding of what does and does not work and, more importantly, provide better insights into the underlying mechanism of action of intervention components [23].

The TCS was used in this review to guide a detailed and systematic evaluation of how theory was reportedly used during intervention development. Future theory-based adherence interventions should utilise the TCS to ensure consistency in reporting [27]. This follows the WIDER (Workgroup for Intervention Development and Evaluation Research) guideline recommendations, which advocate that researchers include detailed descriptions of the underpinning design and proposed mechanism of change, including any psychological theory [81]. Researchers should also draw on the latest guidance, from both research organisations and the field of health psychology, when designing complex theory-based interventions [22, 23, 75, 82].

\subsection{Limitations}

This review was limited to studies published in the English language and delivered to older adults who were prescribed a mean of four or more medications. Given the paucity of adherence research that targets older adults, studies were deemed eligible if the sample population had a mean/median age of 65 years. As study inclusion/exclusion age was not part of the eligibility criteria for this review, studies may have included a small proportion of patients who were aged $<65$ years. However, as noted in Sect. 2.5, the outcome data were not pooled in a metaanalysis and so this was not considered to have any significant implications on the findings of the review. Although extensive electronic and hand-searching strategies were conducted for this review, studies that met the inclusion criteria but were not adequately indexed in the literature may have been missed. The TCS that was used to guide the narrative summary relies solely on details reported by authors in published articles. Studies that made use of theory but failed to report this may also have been overlooked. 


\section{Conclusion}

There is a lack of robust evidence on theory-based adherence interventions targeting older adults prescribed polypharmacy and, therefore, no overall conclusion on their effectiveness can be drawn at this stage. The extent of theory use in developing adherence interventions varied across included studies, and only one study reported theory testing. To enhance the potential effectiveness of theory-based interventions aimed at improving adherence, appropriate background work is essential to inform intervention development. This involves identifying appropriate theories to understand target behaviours before undertaking a systematic process of intervention development and evaluation. The application of theory will ultimately help researchers and clinicians understand the mechanisms of action underlying intervention effects and facilitate additional refinements where necessary.

There is a need for further empirical research that incorporates theory into the intervention development process. If theory is to have a positive impact on intervention effectiveness, it needs to be a core component of the design process as opposed to a loosely applied framework. Those developing theory-based interventions should consider the components of the TCS to help guide theory use and articulate its role in published reports.

\section{Compliance with Ethical Standards}

Funding This work was supported by The Dunhill Medical Trust (Grant Number: R298/0513). The funding body was not involved in the design of the review, data collection, analysis and interpretation of findings or in writing the manuscript.

Conflict of interest Deborah Patton, Carmel Hughes, Cathal Cadogan and Cristín Ryan have no conflicts of interest relevant to the content of this review.

Open Access This article is distributed under the terms of the Creative Commons Attribution-NonCommercial 4.0 International License (http://creativecommons.org/licenses/by-nc/4.0/), which permits any noncommercial use, distribution, and reproduction in any medium, provided you give appropriate credit to the original author(s) and the source, provide a link to the Creative Commons license, and indicate if changes were made.

\section{References}

1. Barnett K, Mercer SW, Norbury M, et al. Epidemiology of multimorbidity and implications for health care, research, and medical education: a cross-sectional study. Lancet. 2012;380:37-43. doi:10.1016/S0140-6736(12)60240-2.

2. Salive ME. Multimorbidity in older adults. Epidemiol Rev. 2013;35:75-83.

3. Tinetti ME, Fried TR, Boyd CM. Designing health care for the most common chronic condition-multimorbidity. JAMA. 2014;307:2493-5.
4. Guthrie B, Makubate B, Hernandez-Santiago V, et al. The rising tide of polypharmacy and drug-drug interactions: population database analysis 1995-2010. BMC Med. 2015;13:74. doi:10. 1186/s12916-015-0322-7.

5. Duerden M, Payne R. Polypharmacy and medicines optimisation: making it safe and sound. The Kings Fund. 2013. http://www. kingsfund.org.uk/publications. Accessed 20 Feb 2016.

6. Rollason V, Vogt N. Reduction of polypharmacy in the elderly: a systematic review of the role of the pharmacist. Drugs Aging. 2003;20:817-32.

7. Patterson S, Cadogen $\mathrm{C}$, Kerse N, et al. Interventions to improve the appropriate use of polypharmacy for older people. Cochrane Database Syst Rev. 2015;(10):CD008165. doi:10.1002/ 14651858.CD008165.pub3.

8. Sabate E. Adherence to long-term therapies: evidence for action. World Health Organisation (WHO). 2003. http://www.who.int/ chp/knowledge/publications/adherence_report/en/. Accessed 28 June 2016.

9. Kardas P, Lewek P, Matyjaszczyk M. Determinants of patient adherence: a review of systematic reviews. Front Pharmacol. 2013;4:91. doi:10.3389/fphar.2013.00091.

10. Linjakumpu T, Hartikainen S, Klaukka T, et al. Use of medications and polypharmacy are increasing among the elderly. J Clin Epidemiol. 2002;55:809-17.

11. Ingersoll KS, Cohen J. The impact of medication regimen factors on adherence to chronic treatment: a review of literature. J Behav Med. 2008;31:213-24.

12. Lehane E, McCarthy G. Intentional and unintentional medication non-adherence: a comprehensive framework for clinical research and practice? A discussion paper. Int $\mathbf{J}$ Nurs Stud. 2007;44:1468-77.

13. Claxton AJ, Cramer J, Pierce CA. A systematic review of the associations between dose regimens and medication compliance. Clin Ther. 2001;23:1296-310.

14. Gellad WF, Grenard JL, Marcum ZA. A systematic review of barriers to medication adherence in the elderly: looking beyond cost and regimen complexity. Am J Geriatr Pharmacother. 2012;9:11-23.

15. Malhotra S, Karan RS, Pandhi P, et al. Drug related medical emergencies in the elderly: role of adverse drug reactions and non-compliance. Postgrad Med J. 2001;913:703-7.

16. DiMatteo MR, Giordani PJ, Lepper HS, et al. Patient adherence and medical treatment outcomes: a meta-analysis. Med Care. 2002;40:794-811.

17. Nieuwlaat R, Wilczynski N, Navarro T, et al. Interventions for enhancing medication adherence, Cochrane Database Syst Rev. 2014;(11):CD000011. doi:10.1002/14651858.CD000011.pub4.

18. Farmer KC. Contemporary issues: methods for measuring and monitoring medication regimen adherence in clinical trials and clinical practice. Clin Ther. 1999;21:1074-90.

19. Horne R, Weinman J, Barber N, et al. Concordance, adherence and compliance in medicine taking, National Coordinating Centre for the Service Delivery and Organisation (NCCSDO). 2005. http://www.netscc.ac.uk/hsdr/files/project/SDO_FR_08-1412076_V01.pdf. Accessed 28 June 2016.

20. Garfield S, Clifford S, Eliasson L, et al. Suitability of measures of self-reported medication adherence for routine clinical use: a systematic review. BMC Med Res Methodol. 2011;11:149. doi:10.1186/1471-2288-11-149.

21. Karve S, Cleves MA, Helm M, et al. Good and poor adherence: optimal cut-point for adherence measures using administrative claims data. Curr Med Res Opin. 2009;25:2303-10.

22. Craig P, Dieppe P, Macintyre S, et al. Developing and evaluating complex interventions: the new Medical Research Council guidance. BMJ. 2008;337:979-83. 
23. Michie SF, Atkins L, West R. The behaviour change wheel: a guide to designing interventions. London: Silverback Publishing; 2015.

24. Michie SF, West R, Campbell R, et al. ABC of behaviour change theories. London: Silverback Publishing; 2014.

25. Glanz K, Rimer BK. Theory at a glance: a guide for health promotion practice. San Francisco: NIH National Cancer Institute; 2005.

26. Ayling K, Brierley S, Johnson B, et al. Efficacy of theory-based interventions for young people with type 1 diabetes: a systematic review and meta-analysis. Br J Health Psychol. 2015;20:428-46.

27. Michie S, Prestwich A. Are interventions theory-based? Development of a theory coding scheme. Health Psychol. 2010;29:1-8.

28. Albarracín D, Gillette JC, Earl AN, et al. A test of major assumptions about behavior change: a comprehensive look at the effects of passive and active HIV-prevention interventions since the beginning of the epidemic. Psychol Bull. 2005;131:856. doi:10.1037/0033-2909.131.6.856.

29. Baban A, Craciun C. Changing health-risk behaviors: a review of theory and evidence-based interventions in health psychology. J Cogn Behav Psychother. 2007;7:45-67.

30. Conn VS, Enriquez M, Ruppar TM, et al. Meta-analyses of theory use in medication adherence intervention research. Am J Health Behav. 2016;40:155-71.

31. Farmer AJ, McSharry J, Rowbotham S, et al. Effects of interventions promoting monitoring of medication use and brief messaging on medication adherence for people with type 2 diabetes: a systematic review of randomized trials. Diabet Med. 2015;33:565-79. doi:10.1111/dme.12987.

32. Prestwich A, Sniehotta FF, Whittington C, et al. Does theory influence the effectiveness of health behavior interventions? Metaanalysis. Health Psychol. 2014;33:465. doi:10.1037/a0032853.

33. Webb T, Joseph J, Yardley L, et al. Using the internet to promote health behavior change: a systematic review and meta-analysis of the impact of theoretical basis, use of behavior change techniques, and mode of delivery on efficacy. J Med Internet Res. 2010;12:e4. doi:10.2196/jmir.1376.

34. The Cochrane Collaboration. Cochrane handbook for systematic reviews of interventions, Version 5.1.0, 2011. http://www. cochrane-handbook.org. Accessed 12 Dec 2015.

35. Moher D, Liberati A, Tetzlaff J, et al. The PRISMA Group (2009) Preferred reporting items for systematic reviews and meta-analyses: the PRISMA statement. PloS Med. 2009;6:e1000097. doi:10.1371/journal.pmed1000097.

36. Effective Practice and Organisation of Care (EPOC). EPOC Resources for review authors, Norwegian Knowledge Centre for the Health Services. 2015. http://epoc.cochrane.org/epocspecific-resources-review-authors. Accessed 12 Dec 2015.

37. Sansone RA, Sansone LA. Alcohol/Substance misuse and treatment nonadherence: fatal attraction. Psychiatry (Edgmont). 2008;5:43.

38. Solomon DH, Iversen MD, Avorn J, et al. Osteoporosis telephonic intervention to improve medication regimen adherence: a large, pragmatic, randomized controlled trial. Arch Intern Med. 2012;172:477-83.

39. Barnason S, Zimmerman L, Hertzog M, et al. Pilot testing of a medication self-management transition intervention for heart failure patients. West J Nurs Res. 2010;32:849-70.

40. Ruppar TM. Randomized pilot study of a behavioral feedback intervention to improve medication adherence in older adults with hypertension. J Cardiovasc Nurs. 2010;25:470-9.

41. Williams A, Manias E, Walker R, et al. A multifactorial intervention to improve blood pressure control in co-existing diabetes and kidney disease: a feasibility randomized controlled trial. J Adv Nurs. 2012;68:2515-25.
42. O'Carroll RE, Chambers JA, Dennis M, et al. Improving adherence to medication in stroke survivors: a pilot randomised controlled trial. Ann Behav Med. 2013;46:358-68.

43. Lancaster GA. Pilot and feasibility studies come of age! Pilot Feasibility Stud. 2015;1:1. doi:10.1186/2055-5784-1-1.

44. Solomon DH, Gleeson T, Iversen M, et al. A blinded randomized controlled trial of motivational interviewing to improve adherence with osteoporosis medications: design of the OPTIMA trial. Osteoporos Int. 2010;21:137-44.

45. Horne R, Weinman J, Hankins M. The beliefs about medicines questionnaire: the development and evaluation of a new method for assessing the cognitive representation of medication. Psychol Health. 1999; 14:1-24.

46. Morisky DE, Green LW, Levine DM. Concurrent and predictive validity of a self-reported measure of medication adherence. Med Care. 1986;24:67-74.

47. Green CP, Porter CB, Bresnahan DR, et al. Development and evaluation of the Kansas City Cardiomyopathy Questionnaire: a new health status measure for heart failure. J Am Coll Cardiol. 2000;35:1245-55.

48. O'Carroll RE, Chambers JA, Dennis M, et al. Improving medication adherence in stroke survivors: mediators and moderators of treatment effects. Health Psychol. 2014;33:1241-50.

49. Bandura A. Social foundations of thought and action: a social cognitive theory. New Jersey: Prentice-Hall; 1986.

50. Murray MD, Morrow DG, Weiner M, et al. A conceptual framework to study medication adherence in older adults. Am J Geriatr Pharmacother. 2004;2:36-43.

51. Leventhal H, Zimmerman R, Gutmann M. Compliance: a selfregulation perspective. In: Gentry W, editor. Handbook of behavioural medicine. New York: Guilford Press; 1984. p. $53-176$.

52. O'Carroll R, Dennis M, Johnston M, et al. Improving adherence to medication in stroke survivors (IAMSS): A randomised controlled trial: study protocol. BMC Neurol. 2010;10:358-68.

53. Hall PA, Fong GT. Temporal self-regulation theory: a model for individual health behavior. Health Psychol Rev. 2007;1:6-52.

54. Prochaska JO, DiClemente CC. Transtheoretical therapy: toward a more integrative model of change. Psychotherapy. 1982;19:276. doi:10.1037/h0088437.

55. Heather N, Rollnick S, Bell A, et al. Effects of brief counselling among male heavy drinkers identified on general hospital wards. Drug Alcohol Rev. 1996;15:29-38.

56. Miller WR. Motivational interviewing: research, practice, and puzzles. Addict Behav. 1996;21:835-42.

57. Williams AF, Manias E, Walker RG. The devil is in the detail-a multifactorial intervention to reduce blood pressure in co-existing diabetes and chronic kidney disease: a single blind, randomized controlled trial. BMC Fam Pract. 2010;11:3. doi:10.1186/14712296-11-3.

58. Rosenstock IM. Historical origins of the health belief model. Health Educ Behav. 1974;2:328-35.

59. Glanz K, Rimer BK, Viswanath K. Health behavior and health education: theory, research, and practice. San Francisco: Wiley; 2008

60. Rosenstock IM, Strecher VJ, Becker MH. Social learning theory and the health belief model. Health Educ Behav. 1988;15:175-83.

61. van Dulmen S, Sluijs E, van Dijk L, et al. Patient adherence to medical treatment: a review of reviews. BMC Health Serv Res. 2007;7:55. doi:10.1186/1472-6963-7-55.

62. Conn VS, Hafdahl AR, Cooper PS, et al. Interventions to improve medication adherence among older adults: meta-analysis of adherence outcomes among randomized controlled trials. Gerontologist. 2009;49:447-62. 
63. Holmes EAF, Hughes DA, Morrison VL. Predicting adherence to medications using health psychology theories: a systematic review of 20 years of empirical research. Value Health. 2014;17:863-76.

64. Arnet I, Abraham I, Messerli M, et al. A method for calculating adherence to polypharmacy from dispensing data records. Int $\mathrm{J}$ Clin Pharm. 2014;36:192-201.

65. Williamson PR, Altman DG, Blazeby JM, et al. Developing core outcome sets for clinical trials: issues to consider. Trials. 2012;13:1-8.

66. Arain M, Campbell MJ, Cooper CL, et al. What is a pilot or feasibility study? a review of current practice and editorial policy. BMC Med Res Methodol. 2010;10:1-7.

67. Thabane L, Ma J, Chu R, et al. A tutorial on pilot studies: the what, why and how. BMC Med Res Methodol. 2010;10:1. doi:10. 1186/1471-2288-10-1.

68. Miller WR, Rollnick S. Motivational interviewing: helping people change. New York: Guilford Press; 2012.

69. Burke BL, Arkowitz H, Menchola M. The efficacy of motivational interviewing: a meta-analysis of controlled clinical trials. J Consult Clin Psychol. 2003;71:843-61.

70. Michie S, Johnston M, Abraham C, et al. Making psychological theory useful for implementing evidence based practice: a consensus approach. Qual Saf Health Care. 2005;14:26-33.

71. Cane J, O'Connor D, Michie S. Validation of the theoretical domains framework for use in behaviour change and implementation research. Implement Sci. 2012;7:37. doi:10.1186/ 1748-5908-7-37.

72. Fisher JD, Fisher WA. Theoretical approaches to individual-level change in HIV risk behavior. In: Peterson JL, DiClemente RJ, editors. Handbook of HIV prevention. New York: Kluwer Academic/Plenum; 2000. p. 3-55.

73. Michie S, Richardson M, Johnston M, et al. The behavior change technique taxonomy (v1) of 93 hierarchically clustered techniques: building an international consensus for the reporting of behavior change interventions. Ann Behav Med. 2013;46:81-95.

74. Cane J, Richardson M, Johnston M, et al. From lists of behaviour change techniques (BCTs) to structured hierarchies: comparison of two methods of developing a hierarchy of BCTs. Br J Health Psychol. 2015;20:130-50.

75. Hughes CM, Cadogan CA, Ryan CA. Development of a pharmacy practice intervention: lessons from the literature. Int J Clin Pharm. 2015:1-6. doi:10.1007/s11096-015-0180-6.

76. Eliasson L, Barber N, Weinman J. Applying COM-B to medication adherence. Eur Health Psychol. 2011;16:7-17.

77. Lopez LM, Tolley EE, Grimes DA, et al. Theory-based interventions for contraception. Cochrane Database Syst Rev. 2011;(3):CD007249. doi:10.1002/14651858.CD007249.pub3.

78. Gourlan M, Bernard P, Bortolon C, et al. Efficacy of theory-based interventions to promote physical activity. A meta-analysis of randomised controlled trials. Health. Psychol Rev. 2015;10:1-17.

79. Colquhoun HL, Brehaut JC, Sales A, et al. A systematic review of the use of theory in randomized controlled trials of audit and feedback. Implement Sci. 2013;8:66. doi:10.1186/1748-5908-866.

80. George J, Elliott RA, Stewart DC. A systematic review of interventions to improve medication taking in elderly patients prescribed multiple medications. Drugs Aging. 2008;25:307-24.

81. Albrecht L, Archibald M, Arseneau D, et al. Development of a checklist to assess the quality of reporting of knowledge translation interventions using the Workgroup for Intervention Development and Evaluation Research (WIDER) recommendations. Implement Sci. 2013;8:52. doi:10.1186/1748-5908-8-52.

82. Stewart D, Klein S. The use of theory in research. Int J Clin Pharm. 2016;38(3):615-9. doi:10.1007/s11096-015-0216-y.

83. Thompson K, Kulkarni J, Sergejew AA. Reliability and validity of a new Medication Adherence Rating Scale (MARS) for the psychoses. Schizophr Res. 2000;42:241-7. 